Published in final edited form as:

Nat Genet. 2015 July 01; 47(7): 803-808. doi:10.1038/ng.3308.

\title{
Transcriptional regulator PRDM12 is essential for human pain perception
}

\author{
A full list of authors and affiliations appears at the end of the article. \\ \# These authors contributed equally to this work.
}

\section{Abstract}

Pain perception has evolved as a warning mechanism to alert organisms to tissue damage and dangerous environments ${ }^{1,2}$. In humans, however, undesirable, excessive or chronic pain is a common and major societal burden for which available medical treatments are currently suboptimal $^{3,4}$. New therapeutic options have recently been derived from studies of individuals with congenital insensitivity to pain (CIP) $)^{5,6}$. Here we identified 10 different homozygous mutations in PRDM12 (encoding PRDI-BF1 and RIZ homology domain-containing protein 12) in subjects with CIP from 11 families. Prdm proteins are a family of epigenetic regulators that control neural specification and neurogenesis ${ }^{7,8}$. We determined that Prdm12 is expressed in nociceptors and their progenitors and participates in the development of sensory neurons in Xenopus embryos. Moreover, CIP-associated mutants abrogate the histone-modifying potential

Correspondence should be addressed to C.G.W. (cw347@cam.ac.uk) or J.S. (jan.senderek@med.uni-muenchen.de). Author Contributions

M.A.-G., Y.P., L.G.-N., W.H., R.M.W., J.M.H., U.M., M.B., D.P., C.M.R., K.v.A., C.F., G.K., M.A.M., J.C.M., S.M.M., A.D.I., U.B.J. and C.G.W. enrolled patients in the study and provided patient care. Y.P., L.G.-N., E.P., J.M.H., E.M.V., P.J.W., M.R.C., C.B., B.R., J.B., P.D.J., M.M.R., R.K., I. Kurth, C.G.W. and J.S. obtained DNA samples, skin biopsies and nerve biopsy specimens. Y.-C.C., M.A.-G., T.M.S., C.W., M.S., T.W., F.S., M.S.N., S.S.S., O.P.C., A.K.N., C.G.W. and J.S. carried out linkage analysis and PRDM12 mutation screening. Y.-C.C., M.Z., C. Samara, A.W.M., R.S. and R.C. performed expression studies on Prdm12. Y.-C.C., S.M., M.Z., C.W., R.S., M.D., C. Stendel, F.R., T.M. and J.S. assessed functional consequences of mutations in PRDM12. A.C.T., A.B.S., I. Katona, J.W. and D.L.H.B. analyzed skin biopsies from CIP patients. S.M. and T.M. performed experiments in Xenopus embryos. Y.C.C., L.T.-Y.C. and G.T.Y. were responsible for experiments involving pluripotent stem cells. R.S. and J.S. carried out protein modeling. A.W.M., R.W., J.W., I. Kurth and D.L.H.B. gave critical advice. M.A.-G., C.G.W. and J.S. oversaw the project, participated in data analysis and directed and supervised the research. The manuscript was written by Y.-C.C., M.A.-G., C.G.W. and J.S. with input from other authors.

Competing Financial Interests

The authors declare no competing financial interests.

Reprints and permissions information is available online at http://www.nature.com/reprints/index.html.

Corrigendum: Transcriptional regulator PRDM12 is essential for human pain perception

Ya-Chun Chen, Michaela Auer-Grumbach, Shinya Matsukawa, Manuela Zitzelsberger, Andreas C Themistocleous, Tim M Strom, Chrysanthi Samara, Adrian W Moore, Lily Ting-Yin Cho, Gareth T Young, Caecilia Weiss, Maria Schabhüttl, Rolf Stucka, Annina B Schmid, Yesim Parman, Luitgard Graul-Neumann, Wolfram Heinritz, Eberhard Passarge, Rosemarie M Watson, Jens Michael Hertz, Ute Moog, Manuela Baumgartner, Enza Maria Valente, Diego Pereira, Carlos M Restrepo, Istvan Katona, Marina Dusl, Claudia Stendel, Thomas Wieland, Fay Stafford, Frank Reimann, Katja von Au, Christian Finke, Patrick J Willems, Michael S Nahorski, Samiha S Shaikh, Ofélia P Carvalho, Adeline K Nicholas, Gulshan Karbani, Maeve A McAleer, Maria Roberta Cilio, John C McHugh, Sinead M Murphy, Alan D Irvine, Uffe Birk Jensen, Reinhard Windhager, Joachim Weis, Carsten Bergmann, Bernd Rautenstrauss, Jonathan Baets, Peter De Jonghe, Mary M Reilly, Regina Kropatsch, Ingo Kurth, Roman Chrast, Tatsuo Michiue, David L H Bennett, C Geoffrey Woods \& Jan Senderek Nat. Genet. 47, 803-808 (2015); published online 25 May 2015; corrected after print 8 July 2015

In the version of this article initially published, there was an error with the affiliations for author Roman Chrast. His correct affiliations are: Department of Medical Genetics, University of Lausanne, Lausanne, Switzerland; Department of Neuroscience, Karolinska Institutet, Stockholm, Sweden; and Department of Clinical Neuroscience, Karolinska Institutet, Stockholm, Sweden. The error has been corrected in the HTML and PDF versions of the article. 
associated with wild-type Prdm12. Prdm12 emerges as a key factor in the orchestration of sensory neurogenesis and may hold promise as a target for new pain therapeutics ${ }^{9,10}$.

We studied two families whose pedigrees were consistent with autosomal recessive CIP. We excluded mutations in the known causative genes for CIP ${ }^{11,12}$ and for clinically similar types of hereditary sensory and autonomic neuropathy (HSAN; types IV and V) ${ }^{13-15}$. SNP arraybased autozygosity mapping in a consanguineous family (family A) identified a single 11.5Mb homozygous region on chromosome 9q33.2-34.13 (Fig. 1a). As this large interval contained almost 150 genes (Supplementary Table 1), we performed exome sequencing on the index patient of family A and the unrelated single CIP patient from family B. Although exome sequencing of the subject from family A yielded no obvious pathogenic variant in genes located in the autozygous region on chromosome 9 , we observed a homozygous missense mutation in one of these positional candidate genes, PRDM12 (NM_021619.2), in the patient from family B (Fig. 1a and Supplementary Fig. 1). We then performed Sanger sequencing of PRDM12 for multiple individuals from family A and identified a homozygous trinucleotide expansion of alanine codons from 12 to 19 in the terminal exon in all affected subjects (Fig. 1a and Supplementary Fig. 1). In an independent approach, we carried out exome sequencing on two individuals from two unrelated families with genetically unclassified CIP, family $\mathrm{C}$ and family D, and identified PRDM12 as the only gene that carried different biallelic missense mutations in both subjects (Fig. 1b and Supplementary Fig. 1). Subsequently, we screened PRDM12 in 158 individuals with autosomal recessive or isolated unexplained CIP or HSAN. We found seven additional unrelated index patients with homozygous PRDM12 mutations. The majority of the variants were missense mutations; however, affected individuals from one family (family $\mathrm{J}$ ) had an 18-alanine repeat mutation, one isolated subject (family E) carried a frame-shift mutation and another isolated individual (family K) had an obligatory splice-site mutation (Fig. 1c and Supplementary Fig. 1). This study was approved by the National Research Ethics Service, NRES Committee East of England-Cambridge Central, the Munich University Medical Research Ethics Committee and the Medical University of Vienna Ethics Committee. Informed consent was obtained from all study subjects or their legal representatives.

$P R D M 12$ is a five-exon gene encoding a single protein isoform of 367 amino acids containing a PR domain (related to the SET methyltransferase domain), three zinc fingers and a C-terminal polyalanine tract (Fig. 1c). The observed point mutations were distributed throughout the gene, altered strictly conserved protein residues and were predicted to interfere with normal protein function (Supplementary Fig. 2, Supplementary Table 2 and Supplementary Note). In all 11 families studied, the PRDM12 mutations segregated as expected for recessive disease alleles (Supplementary Fig. 1). None of the point mutations was present in public SNP databases (1000 Genomes, Exome Variant Server and dbSNP138) or in the institutional exome data sets of Helmholtz Zentrum München and the Cambridge Biomedical Research Campus. These resources together allow for the interrogation of exome data from $>20,000$ individuals. We suspected that the trinucleotide expansions to 18 and 19 alanine codons in two of the families studied here would be deleterious, as other known recessive and X-linked polyalanine expansion diseases in humans manifest clinically when the number of repeats exceeds 15 (refs. 16,17). We found that the length of PRDM12 
polyalanine in the general population is polymorphic, with a maximum of 14 alanines (Fig. 1d and Supplementary Fig. 3). This confirms that the alleles observed in family A and family $\mathrm{J}$ are exceptional.

The phenotype of the affected individuals in the 11 families with PRDM12 mutations was largely consistent: they had been unable to feel acute or inflammatory pain from birth and could not identify noxious heat or cold. Consequently, as infants and children these individuals sustained numerous painless mutilating lesions of the tongue, perioral tissues and fingers due to self-biting, as well as injuries resulting from repeated unnoticed traumatic episodes and burns (Fig. 2a, Supplementary Note and Supplementary Table 3). Corneal reflexes were absent, which led to progressive corneal scarring. In severely affected individuals, recurrent infections of the skin and occasionally of bones and joints had led to bone deformities and neuropathic joints later in life. Notably, large-fiber sensory modalities (light touch, vibration and proprioception) were mostly normal. Sweating and tearing occurred but were substantially reduced with respect to unaffected family members. No other autonomic dysfunction was observed; the senses of smell and hearing were normal. In family $\mathrm{J}$, the phenotype was milder than in the other families and consisted of facial scratching, diabetes-like foot ulcers, intact corneal reflexes and intact sweating and tearing. Heterozygote carriers were all asymptomatic and had normal pain perception. We studied nerve biopsies of CIP patients, done for diagnostic purposes several years before our study, to evaluate peripheral projections of nociceptive sensory neurons (small myelinated $\mathrm{A} \delta$ fibers, normally constituting $30 \%$ of nociceptors, and unmyelinated C fibers, normally constituting $70 \%$ of nociceptors ${ }^{18}$ ). We observed a severe loss of A $\delta$ fibers in the sural nerves of two patients, whereas large-caliber axons for other sensory modalities were largely unaltered (Fig. 2b). Quantitative and qualitative changes in C fibers could not be reliably determined in the nerve biopsies, as no suitable samples for electron microscopy were available (ref. 19 and Supplementary Note). However, results from skin biopsies of two CIP patients suggested that at least the peripheral terminals of $\mathrm{C}$ fibers were affected. We observed a complete absence of nerve fibers crossing the basement membrane to innervate the epidermis (normally representing the terminals of nociceptors and thermoceptors ${ }^{18}$ ), whereas the subepidermal neural plexus and autonomic innervation of sweat glands were reduced compared to what was observed in unaffected individuals but were morphologically grossly normal (Fig. 2c and Supplementary Fig. 4).

Our clinical and histological findings suggested that mutations in PRDM12 cause developmental defects in the sensory neurons that are destined to become nociceptors. Therefore, we explored the expression of Prdm12 during embryogenesis and in human pain neurons generated from stem cells. In mice, expression of Prdm12 (NM_001123362) starts around embryonic day 9.0 (E9.0) in the neural folds, which give rise to neural crest cells (Fig. 3a). The neural crest consists of a transient, multipotent, migratory cell population that develops into various tissues, including the sensory ganglia that contain nociceptor cell bodies $^{20}$. Prdm 12 is prominently expressed in sensory spinal ganglia (dorsal root ganglia (DRG)) but not in sympathetic ganglia during the time when sensory neurons emerge (E10.5-E13.5), mature and differentiate (E14.5-postnatal day 14) ${ }^{21}$ (Fig. 3b and Supplementary Fig. 5a). In addition, we found that $\operatorname{Prdm} 12$ was expressed primarily by neurons rather than by satellite glial cells or Schwann cells in the DRG (Supplementary Fig. 
5b). To assess PRDM12 expression during nociceptor development in humans, we differentiated inducible pluripotent stem cells (iPSCs) into nociceptor-like neurons ${ }^{22,23}$. PRDM12 expression began to increase on day 7 commensurate with neural crest specification. Expression then increased by more than 1,000-fold and peaked at day 9 (Fig. $3 c)$. We examined the electrophysiological properties of these cells after neuronal maturation and confirmed recording of nociceptor-specific tetrodotoxin-resistant sodium current (Supplementary Fig. 6a,b). In addition, nociceptor-like neurons derived from human embryonic stem cells also showed robust induction of PRDM12 expression during differentiation (Supplementary Fig. 6c). Furthermore, we did not find PRDM12 expression in human adult tissues, except in the DRG (Supplementary Fig. 7). Taken together, these findings are consistent with an essential function of Prdm12 during nociceptor neurogenesis (although we note that limited expression of $\operatorname{Prdm} 12$ has also been observed in mouse brain and in spinal cords of mice and zebrafish ${ }^{8,24}$ ). A role for Prdm12 in neural embryogenesis was further supported by a study of Xenopus Prdm12 morphants. Knockdown of the frog ortholog (NM_001079430.1) resulted in an irregular distribution of marker genes of cranial sensory placodes ${ }^{25}$ at the late tailbud stage (stage 28; Fig. 3d), whereas other cranial placodes seemed mostly normal (Supplementary Fig. 8), suggesting that Prdm12 is a universal regulator of sensory neurogenesis in vertebrates.

We next investigated the consequences of CIP-associated mutations for PRDM12 protein function. PRDM12 is a nuclear protein with a diffuse, lace-like pattern. We found that missense mutations affected neither protein expression nor subcellular localization (Supplementary Fig. 9a,b). Conversely, the polyalanine expansion mutation resulted in reduced levels of overexpressed PRDM12 in transfected cells and caused discrete, concentrated foci to form in the nucleus and cytoplasm (Fig. 4a). Expression levels of the polyalanine expansion mutant were recovered upon proteasome inhibition, suggesting that the expansion causes aggregation of PRDM12 and renders the protein less stable and more susceptible to proteolysis, eventually reducing its biological availability within the nucleus. Similar observations have been reported for other pathogenic polyalanine expansions in humans ${ }^{16,17}$. Prdm12 is a member of a family of transcriptional regulators that participate in the control of vertebrate neurogenesis ${ }^{7,8,24-29}$. Unlike other Prdm family members, Prdm12 lacks intrinsic histone methyltransferase activity and recruits the methyltransferase G9a (Ehmt2) to dimethylate histone $\mathrm{H} 3$ at lysine $9(\mathrm{H} 3 \mathrm{~K} 9 \mathrm{me} 2)^{30}$. Histone modifications have emerged as critical epigenetic checkpoints during neurogenesis ${ }^{31-34}$, and aberrant epigenetic mechanisms cause defects in neuronal development, as observed in other human diseases ${ }^{35-38}$. Therefore, we next investigated the effect of PRDM12 mutations on H3K9me2 levels. Overexpression of wild-type Prdm12 robustly increased H3K9me2 in Xenopus neurulastage embryos, whereas the CIP-associated missense Prdm12 mutants did not demonstrate such an effect (Fig. 4b). Also, both human and mouse wild-type Prdm12 strongly induced H3K9me2 in Xenopus embryos, although the mammalian orthologs and the frog protein differed by $\sim 15 \%$ of their amino acids (Supplementary Fig. 10). This supports the hypothesis that PRDM12 missense mutations cause CIP by impairing histone methylation capacity. Mechanistically, we found that the p.His289Leu alteration significantly reduced binding to G9a, whereas the other mutants bound G9a normally (Fig. $4 \mathrm{c}$ and Supplementary Fig. 9c). The putative structure of PRDM12 implies that His289 is 
one of the residues coordinating the zinc ion of the second zinc finger (Fig. 4c), which is required for G9a association ${ }^{30}$. The mechanism by which other Prdm12 mutants interfere with H3K9 dimethylation remains to be determined (Supplementary Fig. 9). Substitutions of Ile102 and Trp160, which are located in the core of the PR domain (Fig. 4d), are likely to alter the domain's structure. Arg168 and Glu172 contribute to the surface of the PR domain. As PR domains represent protein-interaction modules ${ }^{39-42}$, mutations affecting these residues may alter the protein-binding capability of PRDM12-PR.

PRDM12 is essential for the sensing of pain in humans, as pathogenic mutations cause a congenital loss of pain perception. Our data imply that the pathological mechanism involves a loss of control of histone modification during critical points in nociceptor genesis, possibly via G9a or related factors ${ }^{34}$. Increasingly, pathophysiological mechanisms of chronic and neuropathic pain are being found to correlate with epigenetic changes in the peripheral and spinal cord nociceptive circuits ${ }^{9,10}$. The histone-modifying activity of PRDM12 suggests a possible target for new methods of pain relief through reprogramming of the overactive nociceptors.

\section{Methods}

Methods and any associated references are available in the online version of the paper.

\section{Online Methods}

\section{Clinical studies}

Patients were recruited after being seen in the clinic by some of the authors. Mutations in the known causative genes for CIP and clinically similar HSAN ${ }^{11-15}$ (Supplementary Table 4) were ruled out by Sanger sequencing. Eleven patients (P7, P8, P10, P11, P13 and P16-P21) underwent neurophysiological examinations, two (P7 and P11) had a sweat test, two (P3 and $\mathrm{P} 12$ ) had a histamine axonal flare test and one (P3) had a Schirmer test for tear production.

\section{Materials}

Specific reagents were purchased from Sigma-Aldrich unless otherwise indicated. Primary antibodies used in this study are listed in Supplementary Table 5. Primers used for generating expression constructs and for RT-PCR are listed in Supplementary Table 6.

\section{Skin biopsies}

A punch skin biopsy was obtained from the lower leg of P11 (at age 18). The sample was fixed in $2 \%$ periodate-lysine-paraformaldehyde for $24 \mathrm{~h}$ at $4{ }^{\circ} \mathrm{C}$, washed in phosphate buffer and stored in $15 \%$ sucrose with phosphate buffer for $48 \mathrm{~h}$ at $4{ }^{\circ} \mathrm{C}$. A second skin biopsy was obtained from the lower lip of P7 (at age 13) during surgery for perioral injuries. The tissue specimen was fixed in Zamboni's solution for $4 \mathrm{~h}$ at $4{ }^{\circ} \mathrm{C}$, washed in phosphate buffer and stored in $10 \%$ sucrose with phosphate buffer for $24 \mathrm{~h}$ at $4{ }^{\circ} \mathrm{C}$. Skin samples were then embedded in Tissue-Tek O.C.T. Compound (Sakura Finetek), frozen in liquid nitrogen, cut into 50- $\mu \mathrm{m}$ free-floating sections and processed for immunofluorescence microscopy as described $^{43}$. 
Nerve fibers were visualized using rabbit anti-PGP9.5 (Ultraclone, RA 95101) with Cy3conjugated donkey anti-rabbit IgG (Jackson ImmunoResearch, 711-165-152) or Alexa Fluor 488-conjugated goat anti-rabbit IgG (Life Technologies, A-11034). Calcitonin gene-related peptide (CGRP)-immunoreactive nociceptors were assessed by co-staining with rabbit antiPGP9.5 with Alexa Fluor 488-conjugated goat anti-rabbit IgG and sheep anti-CGRP (Enzo Life Sciences, BML-CA1137) with Cy3-conjugated donkey anti-sheep IgG (Stratech, 713-165-003-JIR). Vasoactive intestinal peptide (VIP)-immunoreactive nerve fibers (a subpopulation of autonomic effectors) were detected using rabbit anti-PGP9.5 with Cy3conjugated donkey anti-rabbit IgG and mouse anti-VIP (clone M-19, Santa Cruz, sc-7841) with Alexa Fluor 488-conjugated donkey anti-mouse IgG (Life Technologies, A-21202). To assess myelinated fibers in the lip skin, we stained sections with rabbit anti-PGP9.5 and mouse anti-myelin basic protein (clone SMI-94, Abcam, ab24567) followed by Cy3conjugated donkey anti-rabbit IgG and Alexa Fluor 488-conjugated donkey anti-mouse IgG. Images were taken using an LSM 700 microscope with a Plan-Apochromat objective (Carl Zeiss) at $40 \times$ and $63 \times$ magnification.

\section{Sural nerve biopsies}

Four individuals from different families (P3, P6, P10 and P11) had had diagnostic sural nerve biopsies several years before the current study took place. We were able to reevaluate microscopic images of biopsies from two subjects (P6, biopsied at age 25, and P10, biopsied at age 7). Micrographs of toluidine blue-stained semithin cross-sections of nerve biopsies were used for morphometric evaluation. Myelinated fibers were identified by the observers, and the myelin sheath of each intact fiber was traced manually. In the selection of areas for analysis, care was taken to avoid perineural spaces, blood vessels and fixation artifacts.

\section{Linkage studies}

Autozygosity mapping was performed on four individuals from family A. Genomic DNA samples were processed using Nsp1 250K SNP chips (Affymetrix), and then the allele calls were analyzed with EXCLUDEAR ${ }^{44}$. Only one homozygous region $>1.5 \mathrm{cM}$ was shared by all four individuals.

\section{Whole-exome sequencing}

We carried out targeted exome capture and sequencing of the index patient of family A (P3) and individuals P6 (family B), P7 (family C) and P8 (family D) using a Genome Analyzer HiSeq 2000 system (Illumina). For enrichment of exons and flanking intronic sequences, we used the SureSelect Human All Exon $50 \mathrm{Mb}$ kit (Agilent). We performed 100-bp paired-end runs, which resulted in sequences of $6.4(\mathrm{P} 3), 6.2(\mathrm{P} 6), 8.2(\mathrm{P} 7)$ and $12.3(\mathrm{P} 8) \mathrm{Gb}$. The average read depths were 94 (P3), 93 (P6), 102 (P7) and 156 (P8), with 91\% (P3), 89\% (P6), 95\% (P7) and 97\% (P8) of the targeted regions covered at least 20-fold. Read alignment was performed with BWA (version 0.5.8) to the human genome assembly GRCh37/hg19. Singlenucleotide variants and small insertions and deletions were called with SAMtools. We excluded variants present in dbSNP132 with an average heterozygosity of $>0.02$ (P3, P6) or HapMap SNPs present in dbSNP135 with an average heterozygosity of $>0.02(\mathrm{P} 7, \mathrm{P} 8)$. We next filtered for variants found in any of 100 in-house controls (exomes from individuals with other diseases) or in the 1000 Genomes data (P3, P6) or for variants present in more 
than 8 of $>4,000$ in-house exomes from individuals with unrelated diseases (P7, P8).

Variants were annotated with custom scripts, and we retained only potentially deleterious variants. Only genes containing biallelic variants were considered further.

\section{Mutation detection in additional families}

The $P R D M 12$ coding region and splice sites were amplified using primers designed on the basis of the genomic sequence of PRDM12 (chr9: 133,539,981-133,558,384, GRCh37/hg19 assembly) and the PRDM12 mRNA NM_021619.2 sequence. The primer sequences and PCR conditions are available upon request. Amplicons were purified using NucleoFast PCR clean-up plates (Macherey-Nagel). Sequences of PCR products were determined using the ABI PRISM BigDye Terminator Ready Reaction Cycle Sequencing Kit (Applied Biosystems) and analyzed on an ABI PRISM 3730 DNA Analyzer (Applied Biosystems).

\section{Protein-sequence analysis}

We used PROVEAN ${ }^{45}$, SIFT ${ }^{46}$, MutationTaster2 (ref. 47), PolyPhen-2 (ref. 48) and SNPdryad ${ }^{49}$ to analyze the effects of amino acid substitutions on PRDM12 (Supplementary Table 2). We gathered sequences for homologs to human PRDM12 (NP_067632) by running PSI-BLAST with default settings against the NCBI nonredundant database. We created a multiple-sequence alignment using ClustalW with default settings (Supplementary Fig. 2).

\section{Cloning of expression constructs}

We generated the construct for wildtype human PRDM12 in a pcDNA3 vector by tagging commercially purchased PRDM12 template (Source BioScience) with an N-terminal HA epitope tag. Point mutations were introduced using the QuikChange II Site-Directed Mutagenesis Kit (Agilent). The polyalanine expansion mutations were obtained by overlapextension $\mathrm{PCR}^{50}$. PRDM12 exon 5 harboring the expansion was amplified from patients' genomic DNA using the primers $5^{\prime}$-GCGGCTTCAACTCGCGCA- $3^{\prime}$ and $5^{\prime}$ TCACAGCACCATGGCCGGC- $3^{\prime}$. The remaining coding sequence of PRDM12 was amplified from the wild-type $P R D M 12$ construct using the primers $5^{\prime}$ ATGATGGGCTCCGTGCTCC- $3^{\prime}$ and $5^{\prime}$-TGCGCGAGTTGAAGCCGC- ${ }^{\prime}$. Gel-purified products were used for recombinant PCR with both fragments as the template. The fulllength products were introduced into the pCDNA3 vector with an N-terminal HA tag.

Myc-tagged mouse Prdm12 cDNA (NM_001123362) was generated from mRNA from mouse E13.5 whole embryos and inserted into EcoRI and NotI sites of the mammalian expression vector pCMV-Myc. Mutations were generated using overlap-extension PCR. Mutated sequences were inserted into EcoRI and Notl sites of pCMV-Myc. An expression plasmid for an artificial Prdm12 mutant lacking all three zinc finger motifs (Prdm12 $\Delta \mathrm{ZF})$ was provided by Yoichi Shinkai (RIKEN Institute, Saitama, Japan) and subcloned into pCMV-Myc.

Xenopus laevis Prdm12 cDNA (NM_001079430) was obtained from stage-22 embryos. Generation of an expression construct for Myc-tagged Xenopus Prdm12 in pCS2 vector is described elsewhere (S. Matsukawa et al., in preparation). Mutants of Xenopus Prdm12 were 
obtained by overlap-extension PCR and subcloned into EcoRI and $X b a \mathrm{I}$ sites of the pCS2 vector.

\section{In situ hybridization of mouse embryos}

Mouse embryos (C57BL/6J) were processed for whole-mount and section mRNA in situ hybridization with digoxigenin-labeled probes and signal detection with the chromophoric substrate nitro blue tetrazolium/5-bromo-4-chloro-3-indolyl phosphate (NBT/BCIP; Roche) as described previously ${ }^{8,51}$. The $\operatorname{Prdm} 12$ riboprobe was synthesized from linearized pGEMT Easy plasmid vector containing a partial $\operatorname{Prdm} 12 \mathrm{mRNA}^{8}$.

\section{RT-PCR analysis of mouse Prdm12}

Tissues were collected from wild-type C57BL/6J mice. Dorsal root ganglia (DRG) were isolated when possible (developmental stages E12 and beyond), and whole embryos and neural tubes were used at earlier developmental stages. Sympathetic ganglia were dissected from E13.5 embryos. The mouse Schwann cell line MSC80 (a gift from Professor Roman Chrast, Karolinska Institutet, Stockholm, Sweden) was maintained at low passages and tested negative for mycoplasma. Identity of the cells was determined by detection of Schwann cell markers S100, Gfap, Egr 2 and Mpz. DRG explants and DRG neurons were obtained and cultured as described previously ${ }^{52,53}$. Total RNA was extracted from tissues and cell cultures using the RNeasy Mini Kit (Qiagen). Reverse transcription was performed with the PrimeScript RT Reagent Kit (Takara Bio) or Omniscript RT Kit (Qiagen). For PCR, we used a variety of primers and either GoTaq G2 DNA Polymerase (Promega) or Platinum Taq High-Fidelity Polymerase (Life Technologies). Amplicons were resolved on agarose gels, and DNA bands were imaged under UV light.

\section{PRDM12 expression study in human adult tissues}

Human adult tissue cDNA panels (Human MTC Panels I and II) were purchased from Clontech. PCR was performed using $100 \mathrm{ng}$ of cDNA and Hot Star Master Mix (Qiagen). Amplicons were run and examined on agarose gels, and DNA bands were visualized under UV light.

\section{hESC and iPSC sensory neuron differentiation}

The human embryonic stem cell (hESC) line H9 was obtained from Pfizer (New York, USA), and the iPSC line Sendai F was generated by Neusentis Research Unit (Pfizer, Cambridge, UK). Cell lines were shown to express pluripotency markers by quantitative RTPCR and confirmed to be mycoplasma free before being used for experiments, but they were not further authenticated. hESC and iPSC sensory neuron differentiation was performed as previously reported ${ }^{22,23}$. Cells were seeded as single cells in mTeSR1 (StemCell Technologies) medium on Matrigel (BD Biosciences) $48 \mathrm{~h}$ before neural induction (day 0). KSR medium (390 ml Knockout DMEM, 100 ml Knockout Serum Replacement, 5 ml nonessential amino acids, $5 \mathrm{ml}$ L-glutamine (all from Life Technologies), $3.5 \mathrm{ml} \beta$ mercaptoethanol) containing small-molecule inhibitors LDN193189 $(1 \mu \mathrm{mol} / \mathrm{l})$ and SB-431542 $(10 \mu \mathrm{mol} / \mathrm{l})$ was added to cells from day 0 to day 4 to drive anterior neuroectoderm specification. From day 3, CHIR99021 (3 $\mu \mathrm{mol} / \mathrm{l})$, DAPT $(10 \mu \mathrm{mol} / \mathrm{l})$ and 
SU5402 $(10 \mu \mathrm{mol} / \mathrm{l})$ were added to promote neural crest phenotypes. Cells were fed daily, and N2B27 medium (480 ml neurobasal medium, $5 \mathrm{ml} \mathrm{N}-2$ supplement, $10 \mathrm{ml} \mathrm{B}-27$ supplement, $5 \mathrm{ml} \mathrm{L}$-glutamine (all from Life Technologies), $3.5 \mathrm{ml} \beta$-mercaptoethanol) was added in 25\% increments every other day starting on day 4 (100\% N2B27 medium on day 10). On day 11, maturation medium (N2B27 with human NGF-b BDNF, NT-3 and GDNF, all from Peprotech and used at $25 \mathrm{ng} / \mathrm{ml}$ final concentration) was added and used for longterm culture. Cultures were treated with mitomycin $\mathrm{C}$ to reduce the non-neuronal population.

\section{Quantitative RT-PCR of hESC- and iPSC-derived sensory neurons}

Total RNA was isolated using the RNeasy Mini Kit with on-column DNaseI treatment. Then cDNA was synthesized using a high-capacity RNA-to-cDNA kit (Applied Biosystems). Quantitative RT-PCR was performed using Taqman gene expression mastermix (Applied Biosystems) and customized TILDA cards containing Taqman primer probe sets (Life Technologies) on an ABI PRISM 7900HT machine (Applied Biosystems). Gene expression was analyzed, normalized to that of $G A P D H$ and entered into line graphs or heat maps using Bioconductor packages (Life Technologies).

\section{Electrophysiological recordings of iPSC-derived sensory neurons}

All recordings were performed on fully differentiated iPSC-derived sensory neurons (6 weeks after the addition of growth factor) within 1-2 d of cellular dissociation. Patch-clamp recordings were made using a Multiclamp 700A amplifier (Molecular Devices) and digitized by a Digidata 2000 (Molecular Devices). Glass borosilicate pipettes (Science Products) were used with $R_{\text {pip }}$ of $2-4 \mathrm{M} \Omega$ resulting in $R_{\text {series }}<10 \mathrm{M} \Omega$. Whole-cell capacitances were fully compensated, and series resistance was compensated between $70 \%$ and $80 \%$. Voltage-gated sodium channels were recorded in extracellular solution containing $140 \mathrm{mM} \mathrm{NaCl}, 4 \mathrm{mM}$ $\mathrm{KCl}, 1.8 \mathrm{mM} \mathrm{CaCl}_{2}, 1 \mathrm{mM} \mathrm{MgCl} 2,10 \mathrm{mM}$ HEPES and $5 \mathrm{mM}$ glucose; the $\mathrm{pH}$ was set at 7.4. Pipettes were filled with intracellular solutions containing $140 \mathrm{mM} \mathrm{KCl}, 1.6 \mathrm{mM}$ $\mathrm{MgCl}_{2}, 2.5 \mathrm{mM}$ MgATP, $0.5 \mathrm{mM}$ NaGTP, $2 \mathrm{~m}$ M EGTA and $10 \mathrm{mM}$ HEPES; the $\mathrm{pH}$ was set at 7.3. We elicited sodium currents by stepping the voltage from a holding potential of -120 $\mathrm{mV}$ to $0 \mathrm{mV}$ for $100 \mathrm{~ms}$. Functions of ion channels were further characterized by the application of tetrodotoxin.

\section{Xenopus embryo manipulation}

The developmental stages mentioned in this study correspond to the stages of normal Xenopus laevis development ${ }^{54}$. For the preparation of mRNAs for microinjections, pCS2 plasmid vectors containing wild-type and mutated $\operatorname{Prdm} 12 \mathrm{cDNA}$ were linearized and transcribed with the mMESSAGE mMACHINE SP6 transcription kit (Life Technologies). Morpholino antisense oligomers (MOs) were obtained from Gene Tools. The control MO and the Prdm12 MO had sequences 5' -CCTCTTACCTCAGTTA CAATTTATA-3' and 5' GCAGCACCGAGCCCATCATTAA TTC- ${ }^{\prime}$, respectively. Embryos were obtained by artificial fertilization and dejellied with $4.6 \%$ L-cysteine hydrochloride at $\mathrm{pH} 7.8$ during the one-cell stage. Synthesized mRNAs and MOs were microinjected with a Pico-Injector PLI-100 (Harvard Apparatus) into embryos at the two-cell stage. MO injection was lethal in 5\% (control MO) and 20\% (Prdm12 MO) of embryos. 
To confirm the efficiency of the Prdm12 MO, we co-injected embryos with Myc-Prdm 12 mRNA ( $1 \mathrm{ng} / \mathrm{embryo}$ ) and control or Prdm12 MO (5, 10 and $20 \mathrm{ng} / \mathrm{embryo})$. Protein extracts were prepared in RIPA buffer ( $1 \%$ NP-40, $1 \%$ sodium deoxycholate, $0.1 \%$ SDS, $150 \mathrm{mM}$ $\mathrm{NaCl}, 25 \mathrm{mM}$ Tris-HCl, $\mathrm{pH}$ 7.4) at stage 26. Proteins were separated by SDS-PAGE, blotted onto Hybond-C membranes (GE Healthcare) and visualized using mouse anti-Myc (clone 9E10, Santa Cruz, sc-40) and mouse anti-a-tubulin (clone DM1A, Sigma-Aldrich, T9026) followed by HRP-conjugated goat anti-mouse IgG (Thermo Fisher, PI32230). Signals were obtained using Luminata Forte Western substrate (Millipore). For assessment of the distribution pattern of cranial placode markers, embryos were injected with $20 \mathrm{ng}$ control or Prdm12 MO per embryo.

\section{Whole-mount in situ hybridization of Xenopus embryos}

For preparation of riboprobes for Prdm 12 and cranial placode markers, pBluescript-SKPrdm12, pCS2p-Islet1, pBluescript-SK-Ebf3, pBluescript-SK-Ath3, pGEM-Pax6, pBluescript-SK-Six 3 and pCS2-Pax 8 were linearized and used as templates. Probes were synthesized with T7 RNA polymerase and labeled with digoxigenin using the DIG RNA labeling kit (Roche). Whole-mount in situ hybridization was performed at the late tailbud stage (stage 26 or stage 28 ) with a modified Harland's protocol ${ }^{55}$ using NBT/BCIP as the chromophoric substrate. The distribution pattern of markers was determined by visual inspection; for MO-injected embryos, patterns were categorized into three main types (at least 40 live embryos per condition).

\section{Histone methylation studies}

Wnt8, Chrd (for inducing neural crest-like cells ${ }^{56}$; each $0.05 \mathrm{ng} / \mathrm{embryo}$ ) and Prdm12 (wild type and CIP-associated mutations, $1 \mathrm{ng} / \mathrm{embryo}$ ) mRNAs were co-injected. The ectoderm region (animal cap) of the injected embryos was dissected at the blastula stage and cultured until the mid-neurula stage (stage 15). Cell lysates were prepared in RIPA buffer, and proteins were resolved by SDS-PAGE. Immunoblotting was done using transfer to Hybond$\mathrm{C}$ membranes and incubation with mouse anti-Myc (clone 9E10, Santa Cruz, sc-40), mouse anti-H3K9me2 (clone RR202, Millipore, 05-685) and rabbit anti-H3 (Millipore, 07-690) followed by HRP-conjugated goat anti-mouse IgG and HRP-conjugated goat anti-rabbit IgG (Thermo Fisher, PI32260). Signals were obtained using Luminata Forte Western HRP substrate (Millipore).

\section{Expression levels of exogenous Prdm12}

COS-7 cells were purchased from Sigma-Aldrich and maintained at low passages. The cell line tested negative for mycoplasma but was not further authenticated. Cells were cultured in DMEM containing 10\% fetal bovine serum and $2 \mathrm{mM}$ L-glutamine (Life Technologies).

JetPei Transfection Reagent (Peqlab) was used to co-transfect cells with human (HA-tagged) and mouse (Myc-tagged) Prdm12 expression constructs and a GFP plasmid (control for transfection efficiency). Cells were lysed in lysis buffer (1\% SDS, $10 \mathrm{mM}$ Tris, pH 7.4) or RIPA buffer $24 \mathrm{~h}$ after transfection. The pellet remaining after extraction with RIPA buffer was sonicated and resuspended in RIPA buffer. To explore a potential effect of proteasomal degradation on Prdm12 turnover, we treated cells with $5 \mu \mathrm{M}$ MG132. Proteins were resolved by SDS-PAGE and blotted onto Protran membranes (GE Healthcare). Immunoblots were 
developed by incubation with mouse anti-Myc (clone 9E10, Clontech, 631206), mouse antiHA (clone 16B12, Covance, MMS-101P-200), rabbit anti-GFP (Abcam, ab290) and rabbit anti-a-tubulin (Cell Signaling, 2144), followed by incubation with HRP-conjugated rabbit anti-mouse IgG (Dako, P0260) and HRP-conjugated goat anti-rabbit IgG (Cell Signaling, 7074). Signals were obtained using enhanced chemiluminescence (ECL) (GE Healthcare). Densitometry to quantify Prdm12 expression was performed using ImageJ software. Signals obtained for Prdm12 were normalized to signals for GFP and a-tubulin.

\section{Interaction of Prdm12 with G9a}

COS-7 cells were cultured as described above and co-transfected with human FLAG-tagged G9a (a gift from Chenfang Dong, University of Kentucky, Lexington, Kentucky, USA) and mouse Myc-Prdm12 using JetPei Transfection Reagent. Total cellular protein was collected after $48 \mathrm{~h}$ in lysis buffer (1× PBS, $5 \mathrm{mM}$ EDTA, $0.5 \%$ NP-40) and incubated with mouse anti-Myc cross-linked to protein A agarose beads (Clontech) at $4{ }^{\circ} \mathrm{C}$ overnight. Beads were recovered by centrifugation and washed five times with PBS. Bound proteins were eluted in SDS sample buffer for $10 \mathrm{~min}$ at $98^{\circ} \mathrm{C}$, resolved by SDS-PAGE and blotted onto Hybond-C membranes. Proteins were detected using mouse anti-Myc (clone 9E10, Clontech, 631206) and mouse anti-FLAG (clone M2, Sigma-Aldrich, F3165) followed by HRP-conjugated rabbit anti-mouse IgG. Signals were obtained using ECL and quantified with ImageJ. The amount of co-immunoprecipitated FLAG-G9a was normalized to the amount of MycPrdm12 in the immunoprecipitation fraction and G9a in whole-cell extracts.

\section{Chromatin fractionation}

COS-7 cells were cultured as described above and transfected with human HA-PRDM12 using JetPei Transfection Reagent. The day after transfection, cells were lysed in CSK buffer (10 mM HEPES, $150 \mathrm{mM} \mathrm{NaCl}, 300 \mathrm{mM}$ sucrose, $1 \mathrm{mM} \mathrm{MgCl} 2,1 \mathrm{mM} \mathrm{Mg}$-ATP, $1 \mathrm{mM}$ EGTA, 1 mM DTT, $1 \%$ Triton X-100, pH 7.5). Cell extracts were separated into chromatinbound and soluble protein fractions by centrifugation at $4,000 \mathrm{rpm}$ at $4{ }^{\circ} \mathrm{C}$ for $5 \mathrm{~min}$. Fractions were subjected to SDS-PAGE and blotted onto Protran membranes. Proteins were detected using mouse anti-HA, rabbit anti-a-tubulin (Cell Signaling, 2144) and rabbit antiacetylated histone 3 (Cell Signaling, 9677) followed by HRP-conjugated rabbit anti-mouse IgG and HRP-conjugated goat anti-rabbit IgG (Cell Signaling, 7074). Signals were obtained using ECL.

\section{Subcellular localization studies}

HEK-293T cells were purchased from Sigma-Aldrich and maintained at low passages. The cell line tested negative for mycoplasma but was not further authenticated. Cells were seeded onto glass coverslips coated with poly-L-lysine at a density of $1.5 \times 10^{5}$ cells per coverslip and cultured in DMEM containing 10\% fetal bovine serum and $4 \mathrm{mM} \mathrm{L}$-glutamine for $24 \mathrm{~h}$. Cells were transfected with human HA-PRDM12 using X-tremeGene HP DNA reagent (Roche). After $24 \mathrm{~h}$, the cells were fixed with $4 \%$ paraformaldehyde, permeabilized with $0.2 \%$ Triton X-100, blocked in 3\% BSA and incubated with mouse anti-HA and Alexa Fluor 546-conjugated rabbit anti-mouse IgG (Life Technologies, A-11060). The cells were mounted in ProLong Gold antifade reagent (Life Technologies) and examined using an LSM 510 microscope (Carl Zeiss). 


\section{Structural model of PRDM12}

We modeled PRDM12 using the crystal structures of PRDM1, PRDM9 (for the PR domain) and ZNF406 (for the second zinc finger domain) as templates (Protein Data Bank accession codes 3dal, 4ijd and 2els) using the Swiss-PdbViewer software.

\section{Statistical analysis}

Data are presented as mean \pm s.d. Statistical significance was calculated using an unpaired, two-sided Welch's $t$-test (parametric data) or a two-sided Mann-Whitney $U$-test (nonparametric data). Significance was set at $* P<0.05$, $* * P<0.01$ or $* * * P<0.001$.

\section{Supplementary Material}

Refer to Web version on PubMed Central for supplementary material.

\section{Authors}

Ya-Chun Chen $\# 1,2$, Michaela Auer-Grumbach \#3, Shinya Matsukawa ${ }^{4}$, Manuela Zitzelsberger ${ }^{5}$, Andreas C Themistocleous ${ }^{6,7}$, Tim M Strom ${ }^{8,9}$, Chrysanthi Samara ${ }^{10}$, Adrian W Moore ${ }^{11}$, Lily Ting-Yin Cho ${ }^{12}$, Gareth T Young ${ }^{12}$, Caecilia Weiss $^{5}$, Maria Schabhüttl ${ }^{3}$, Rolf Stucka ${ }^{5}$, Annina B Schmid ${ }^{6,13}$, Yesim Parman ${ }^{14}$, Luitgard Graul-Neumann ${ }^{15}$, Wolfram Heinritz ${ }^{16,17}$, Eberhard Passarge ${ }^{17,18}$, Rosemarie M Watson ${ }^{19}$, Jens Michael Hertz ${ }^{20}$, Ute Moog ${ }^{21}$, Manuela Baumgartner ${ }^{22}$, Enza Maria Valente ${ }^{23}$, Diego Pereira ${ }^{24}$, Carlos M Restrepo ${ }^{25}$, Istvan Katona ${ }^{26}$, Marina Dus $\left.\right|^{5}$, Claudia Stende $\left.\right|^{5,27}$, Thomas Wieland ${ }^{8}$, Fay Stafford $^{1,2}$, Frank Reimann ${ }^{28}$, Katja von $\mathrm{Au}^{29}$, Christian Finke ${ }^{30}$, Patrick J Willems $^{31}$, Michael S Nahorski ${ }^{1,2}$, Samiha S Shaikh ${ }^{1,2}$, Ofélia P Carvalho ${ }^{1,2}$, Adeline K Nicholas ${ }^{2}$, Gulshan Karbani ${ }^{32}$, Maeve A McAleer ${ }^{19}$, Maria Roberta Cilio $^{33,34}$, John C McHugh ${ }^{35}$, Sinead M Murphy ${ }^{36,37}$, Alan D Irvine ${ }^{19,38}$, Uffe Birk Jensen $^{39}$, Reinhard Windhager ${ }^{3}$, Joachim Weis ${ }^{26}$, Carsten Bergmann ${ }^{40,41,42}$, Bernd Rautenstrauss ${ }^{5,43}$, Jonathan Baets ${ }^{44,45,46}$, Peter De Jonghe ${ }^{44,45,46}$, Mary M Reilly ${ }^{47}$, Regina Kropatsch ${ }^{48}$, Ingo Kurth ${ }^{49}$, Roman Chrast ${ }^{10,50,51}$, Tatsuo Michiue ${ }^{4}$, David L H Bennett ${ }^{6}$, C Geoffrey Woods ${ }^{1,2}$, Jan Senderek ${ }^{5}$

\section{Affiliations}

${ }^{1}$ Department of Medical Genetics, University of Cambridge, Cambridge, UK ${ }^{2}$ Cambridge Institute for Medical Research, University of Cambridge, Cambridge, UK ${ }^{3}$ Department of Orthopaedics, Medical University Vienna, Vienna, Austria ${ }^{4}$ Department of Life Sciences, Graduate School of Arts and Sciences, University of Tokyo, Tokyo, Japan ${ }^{5}$ Friedrich-Baur-Institute, Ludwig Maximilians University Munich, Munich, Germany ${ }^{6}$ Nuffield Department of Clinical Neurosciences, University of Oxford, Oxford, UK ${ }^{7}$ Brain Function Research Group, School of Physiology, Faculty of Health Sciences, University of the Witwatersrand, Johannesburg, South Africa ${ }^{8}$ Institute of Human Genetics, Helmholtz Zentrum München, Neuherberg, Germany ${ }^{9}$ Institute of Human Genetics, Technische Universität München, Munich, Germany ${ }^{10}$ Department of Medical Genetics, 
University of Lausanne, Lausanne, Switzerland ${ }^{11}$ Disease Mechanism Research Core, RIKEN Brain Science Institute, Saitama, Japan ${ }^{12}$ Neusentis Research Unit, Pfizer, Cambridge, UK ${ }^{13}$ School of Health and Rehabilitation Sciences, The University of Queensland, St. Lucia, Australia ${ }^{14}$ Department of Neurology, Istanbul University, Istanbul, Turkey ${ }^{15} \mathrm{Ambulantes}$ Gesundheitszentrum der Charité Campus Virchow (Humangenetik), Universitätsmedizin Berlin, Berlin, Germany ${ }^{16}$ Praxis für Humangenetik Cottbus, Cottbus, Germany ${ }^{17}$ Institut für Humangenetik, Universitätsklinikum Leipzig, Leipzig, Germany ${ }^{18}$ Institut für Humangenetik, Universitätsklinikum Essen, Essen, Germany ${ }^{19}$ Department of Dermatology, Our Lady's Children's Hospital, Dublin, Ireland ${ }^{20}$ Department of Clinical Genetics, Odense University Hospital, Odense, Denmark ${ }^{21}$ Institute of Human Genetics, Heidelberg University, Heidelberg, Germany ${ }^{22}$ Neuropädiatrische Ambulanz, Krankenhaus der Barmherzigen Schwestern Linz, Linz, Austria ${ }^{23}$ Neurogenetics Unit, Casa Sollievo della Sofferenza, San Giovanni Rotondo, Italy ${ }^{24}$ Departamento de Cirugía Plástica, Hospital Infantil Universitario de San José, Bogotá, Colombia ${ }^{25}$ Unidad de Genética, Universidad del Rosario, Bogotá, Colombia ${ }^{26}$ Institut für Neuropathologie, Uniklinik RWTH Aachen, Aachen, Germany ${ }^{27}$ German Center for Neurodegenerative Diseases (DZNE), Munich, Germany ${ }^{28}$ Department of Clinical Biochemistry, University of Cambridge, Cambridge, UK ${ }^{29} \mathrm{SPZ}$ Neuropädiatrie Charité, Universitätsmedizin Berlin, Berlin, Germany ${ }^{30}$ CharitéCentrum für Zahn-, Mund- und Kieferheilkunde, Arbeitsbereich Kinderzahnmedizin, Universitätsmedizin Berlin, Berlin, Germany ${ }^{31}$ GENDIA (GENetic DIAgnostic Network), Antwerp, Belgium ${ }^{32}$ Yorkshire Regional Genetics Service, Chapel Allerton Hospital, Leeds, UK ${ }^{33}$ Department of Neurology, University of California San Francisco, San Francisco, California, USA ${ }^{34}$ Department of Neuroscience, Bambino Gesù Children's Hospital and Research Institute, Rome, Italy ${ }^{35}$ Department of Neurology and Neurophysiology, Our Lady's Children's Hospital, Dublin, Ireland ${ }^{36}$ Department of Neurology, Adelaide \& Meath Hospital, Dublin, Ireland ${ }^{37}$ Academic Unit of Neurology, Trinity College, Dublin, Ireland ${ }^{38}$ Clinical Medicine, Trinity College, Dublin, Ireland ${ }^{39}$ Department of Clinical Genetics, Aarhus University Hospital, Aarhus, Denmark ${ }^{40}$ Center for Human Genetics, Bioscientia, Ingelheim, Germany ${ }^{41}$ Department of Medicine, Renal Division, Freiburg University Medical Center, Freiburg, Germany ${ }^{42}$ Center for Clinical Research, Freiburg University Medical Center, Freiburg, Germany ${ }^{43}$ Medizinisch Genetisches Zentrum, Munich, Germany ${ }^{44}$ Neurogenetics Group, VIB Department of Molecular Genetics, University of Antwerp, Antwerp, Belgium ${ }^{45}$ Laboratory of Neurogenetics, Institute Born-Bunge, University of Antwerp, Antwerp, Belgium ${ }^{46}$ Department of Neurology, Antwerp University Hospital, Antwerp, Belgium ${ }^{47}$ MRC Centre for Neuromuscular Diseases, UCL Institute of Neurology, National Hospital for Neurology, London, UK ${ }^{48}$ Department of Human Genetics, Ruhr-University Bochum, Bochum, Germany ${ }^{49}$ Institute of Human Genetics, Jena University Hospital, Jena, Germany ${ }^{50}$ Department of Neuroscience, Karolinska Institutet, Stockholm, Sweden

${ }^{51}$ Department of Clinical Neuroscience, Karolinska Institutet, Stockholm, Sweden 


\section{Acknowledgments}

The authors are grateful for the participation of the patients and their families in this study. The help of all contributing medical, technical and administrative staff is greatly appreciated. We thank S. Malik for her invaluable work with family A, J.R.P. Madrid and F. Axelrod for advice and discussion and M.F. Passarge for helpful suggestions on the text. D.L.H.B. is a senior Wellcome Clinical Scientist (ref. no. 095698z/11/z). This work was supported by Cambridge NIHR Biomedical Research Centre (Y.-C.C., F.S. and C.G.W.), Austrian Science Fond (P23223-B19 to M.A.-G.), the UK Medical Research Council (M.S.N. and S.S.S.), Association Belge contre les Maladies Neuromusculaires and EU FP7/2007-2013 (grant 2012-305121 (NEUROMICS) to J.B. and P.D.J.), Deutsche Forschungsgemeinschaft (CRC/SFB 1140 to C.B. and KU1587/4-1 to I. Kurth), Gebert-Rüf Stiftung (GRS-046/09 to R.C. and J.S.), and Friedrich-Baur Stiftung (J.S.).

\section{References}

1. Merskey H, Watson GD. The lateralisation of pain. Pain. 1979; 7:271-280. [PubMed: 394109]

2. Bennett DL, Woods CG. Painful and painless channelopathies. Lancet Neurol. 2014; 13:587-599. [PubMed: 24813307]

3. Stewart WF, Ricci JA, Chee E, Morganstein D, Lipton R. Lost productive time and cost due to common pain conditions in the US workforce. J Am Med Assoc. 2003; 290:2443-2454.

4. Breivik H, Collett B, Ventafridda V, Cohen R, Gallacher D. Survey of chronic pain in Europe: prevalence, impact on daily life, and treatment. Eur J Pain. 2006; 10:287-333. [PubMed: 16095934]

5. Goldberg YP, et al. Human Mendelian pain disorders: a key to discovery and validation of novel analgesics. Clin Genet. 2012; 82:367-373. [PubMed: 22845492]

6. Holmes D. Anti-NGF painkillers back on track? Nat Rev Drug Discov. 2012; 11:337-338. [PubMed: 22543456]

7. Hohenauer T, Moore AW. The Prdm family: expanding roles in stem cells and development. Development. 2012; 139:2267-2282. [PubMed: 22669819]

8. Kinameri E, et al. Prdm proto-oncogene transcription factor family expression and interaction with the Notch-Hes pathway in mouse neurogenesis. PLoS One. 2008; 3:e3859. [PubMed: 19050759]

9. Crow M, Denk F, McMahon SB. Genes and epigenetic processes as prospective pain targets. Genome Med. 2013; 5:12. [PubMed: 23409739]

10. Denk F, McMahon SB. Chronic pain: emerging evidence for the involvement of epigenetics. Neuron. 2012; 73:435-444. [PubMed: 22325197]

11. Cox JJ, et al. An $S C N 9 A$ channelopathy causes congenital inability to experience pain. Nature. 2006; 444:894-898. [PubMed: 17167479]

12. Leipold E, et al. A de novo gain-of-function mutation in SCN11A causes loss of pain perception. Nat Genet. 2013; 45:1399-1404. [PubMed: 24036948]

13. Indo Y, et al. Mutations in the TRKA/NGF receptor gene in patients with congenital insensitivity to pain with anhidrosis. Nat Genet. 1996; 13:485-488. [PubMed: 8696348]

14. Einarsdottir E, et al. A mutation in the nerve growth factor beta gene (NGFB) causes loss of pain perception. Hum Mol Genet. 2004; 13:799-805. [PubMed: 14976160]

15. Carvalho OP, et al. A novel NGF mutation clarifies the molecular mechanism and extends the phenotypic spectrum of the HSAN5 neuropathy. J Med Genet. 2011; 48:131-135. [PubMed: 20978020]

16. Albrecht A, Mundlos S. The other trinucleotide repeat: polyalanine expansion disorders. Curr Opin Genet Dev. 2005; 15:285-293. [PubMed: 15917204]

17. Hughes J, et al. Mechanistic insight into the pathology of polyalanine expansion disorders revealed by a mouse model for X linked hypopituitarism. PLoS Genet. 2013; 9:e1003290. [PubMed: 23505376]

18. Dubin AE, Patapoutian A. Nociceptors: the sensors of the pain pathway. J Clin Invest. 2010; 120:3760-3772. [PubMed: 21041958]

19. Ochoa J, Mair WG. The normal sural nerve in man. I. Ultrastructure and numbers of fibres and cells. Acta Neuropathol. 1969; 13:197-216. [PubMed: 5805973] 
20. Hall BK. The neural crest and neural crest cells: discovery and significance for theories of embryonic organization. J Biosci. 2008; 33:781-793. [PubMed: 19179766]

21. Ma Q, Fode C, Guillemot F, Anderson DJ. Neurogenin1 and neurogenin2 control two distinct waves of neurogenesis in developing dorsal root ganglia. Genes Dev. 1999; 13:1717-1728. [PubMed: 10398684]

22. Chambers SM, et al. Combined small-molecule inhibition accelerates developmental timing and converts human pluripotent stem cells into nociceptors. Nat Biotechnol. 2012; 30:715-720. [PubMed: 22750882]

23. Young GT, et al. Characterizing human stem cell-derived sensory neurons at the single-cell level reveals their ion channel expression and utility in pain research. Mol Ther. 2014; 22:1530-1543. [PubMed: 24832007]

24. Zannino DA, Downes GB, Sagerström CG. Prdm12b specifies the p1 progenitor domain and reveals a role for V1 interneurons in swim movements. Dev Biol. 2014; 390:247-260. [PubMed: 24631215]

25. Schlosser G. Induction and specification of cranial placodes. Dev Biol. 2006; 294:303-351. [PubMed: 16677629]

26. Moore AW, Jan LY, Jan YN. Hamlet, a binary genetic switch between single- and multipledendrite neuron morphology. Science. 2002; 297:1355-1358. [PubMed: 12193790]

27. Rossi CC, Kaji T, Artinger KB. Transcriptional control of Rohon-Beard sensory neuron development at the neural plate border. Dev Dyn. 2009; 238:931-943. [PubMed: 19301392]

28. Endo K, et al. Chromatin modification of Notch targets in olfactory receptor neuron diversification. Nat Neurosci. 2012; 15:224-233.

29. Chittka A, Nitarska J, Grazini U, Richardson WD. Transcription factor positive regulatory domain 4 (PRDM4) recruits protein arginine methyltransferase 5 (PRMT5) to mediate histone arginine methylation and control neural stem cell proliferation and differentiation. J Biol Chem. 2012; 287:42995-43006. [PubMed: 23048031]

30. Yang CM, Shinkai Y. Prdm12 is induced by retinoic acid and exhibits anti-proliferative properties through the cell cycle modulation of P19 embryonic carcinoma cells. Cell Struct Funct. 2013; 38:197-206. [PubMed: 23856557]

31. Hu XL, Wang Y, Shen Q. Epigenetic control on cell fate choice in neural stem cells. Protein Cell. 2012; 3:278-290. [PubMed: 22549586]

32. Tan SL, et al. Essential roles of the histone methyltransferase ESET in the epigenetic control of neural progenitor cells during development. Development. 2012; 139:3806-3816. [PubMed: 22991445]

33. Jobe EM, McQuate AL, Zhao X. Crosstalk among epigenetic pathways regulates neurogenesis. Front Neurosci. 2012; 6:59. [PubMed: 22586361]

34. Boshnjaku V, et al. Epigenetic regulation of sensory neurogenesis in the dorsal root ganglion cell line ND7 by folic acid. Epigenetics. 2011; 6:1207-1216. [PubMed: 21931278]

35. Amir RE, et al. Rett syndrome is caused by mutations in X-linked $M E C P 2$, encoding methyl-CpGbinding protein 2. Nat Genet. 1999; 23:185-188. [PubMed: 10508514]

36. Kleefstra T, et al. Loss-of-function mutations in euchromatin histone methyl transferase 1 (EHMT1) cause the 9q34 subtelomeric deletion syndrome. Am J Hum Genet. 2006; 79:370-377. [PubMed: 16826528]

37. Klein CJ, et al. Mutations in DNMT1 cause hereditary sensory neuropathy with dementia and hearing loss. Nat Genet. 2011; 43:595-600. [PubMed: 21532572]

38. Jakovcevski M, Akbarian S. Epigenetic mechanisms in neurological disease. Nat Med. 2012; 18:1194-1204. [PubMed: 22869198]

39. Huang S, Shao G, Liu L. The PR domain of the Rb-binding zinc finger protein RIZ1 is a protein binding interface and is related to the SET domain functioning in chromatin-mediated gene expression. J Biol Chem. 1998; 273:15933-15939. [PubMed: 9632640]

40. Rozenblatt-Rosen O, et al. The C-terminal SET domains of ALL-1 and TRITHORAX interact with the INI1 and SNR1 proteins, components of the SWI/SNF complex. Proc Natl Acad Sci USA. 1998; 95:4152-4157. [PubMed: 9539705] 
41. Cui X, et al. Association of SET domain and myotubularin-related proteins modulates growth control. Nat Genet. 1998; 18:331-337. [PubMed: 9537414]

42. Cardoso C, et al. Specific interaction between the XNP/ATR-X gene product and the SET domain of the human EZH2 protein. Hum Mol Genet. 1998; 7:679-684. [PubMed: 9499421]

43. Doppler K, Werner C, Sommer C. Disruption of nodal architecture in skin biopsies of patients with demyelinating neuropathies. J Peripher Nerv Syst. 2013; 18:168-176. [PubMed: 23781964]

44. Nicholas AK, et al. The molecular landscape of ASPM mutations in primary microcephaly. J Med Genet. 2009; 46:249-253. [PubMed: 19028728]

45. Choi Y, Sims GE, Murphy S, Miller JR, Chan AP. Predicting the functional effect of amino acid substitutions and indels. PLoS One. 2012; 7:e46688. [PubMed: 23056405]

46. Ng PC, Henikoff S. Accounting for human polymorphisms predicted to affect protein function. Genome Res. 2002; 12:436-446. [PubMed: 11875032]

47. Schwarz JM, Cooper DN, Schuelke M, Seelow D. MutationTaster2: mutation prediction for the deep-sequencing age. Nat Methods. 2014; 11:361-362. [PubMed: 24681721]

48. Adzhubei IA, et al. A method and server for predicting damaging missense mutations. Nat Methods. 2010; 7:248-249. [PubMed: 20354512]

49. Wong KC, Zhang Z. SNPdryad: predicting deleterious non-synonymous human SNPs using only orthologous protein sequences. Bioinformatics. 2014; 30:1112-1119. [PubMed: 24389653]

50. Higuchi R, Krummel B, Saiki R. A general method of in vitro preparation and specific mutagenesis of DNA fragments: study of protein and DNA interactions. Nucleic Acids Res. 1988; 16:73517367. [PubMed: 3045756]

51. Grove EA, Tole S, Limon J, Yip L, Ragsdale CW. The hem of the embryonic cerebral cortex is defined by the expression of multiple Wnt genes and is compromised in Gli3-deficient mice. Development. 1998; 125:2315-2325. [PubMed: 9584130]

52. Stendel C, et al. SH3TC2, a protein mutant in Charcot-Marie-Tooth neuropathy, links peripheral nerve myelination to endosomal recycling. Brain. 2010; 133:2462-2474. [PubMed: 20826437]

53. Arnaud E, et al. SH3TC2/KIAA1985 protein is required for proper myelination and the integrity of the node of Ranvier in the peripheral nervous system. Proc Natl Acad Sci USA. 2009; 106:1752817533. [PubMed: 19805030]

54. Nieuwkoop, PD, Faber, J. Normal Table of Xenopus Embryos. North-Holland: 1967.

55. Harland RM. In situ hybridization: an improved whole-mount method for Xenopus embryos. Methods Cell Biol. 1991; 36:685-695. [PubMed: 1811161]

56. Sato T, Sasai N, Sasai Y. Neural crest determination by co-activation of Pax 3 and Zic1 genes in Xenopus ectoderm. Development. 2005; 132:2355-2363. [PubMed: 15843410] 


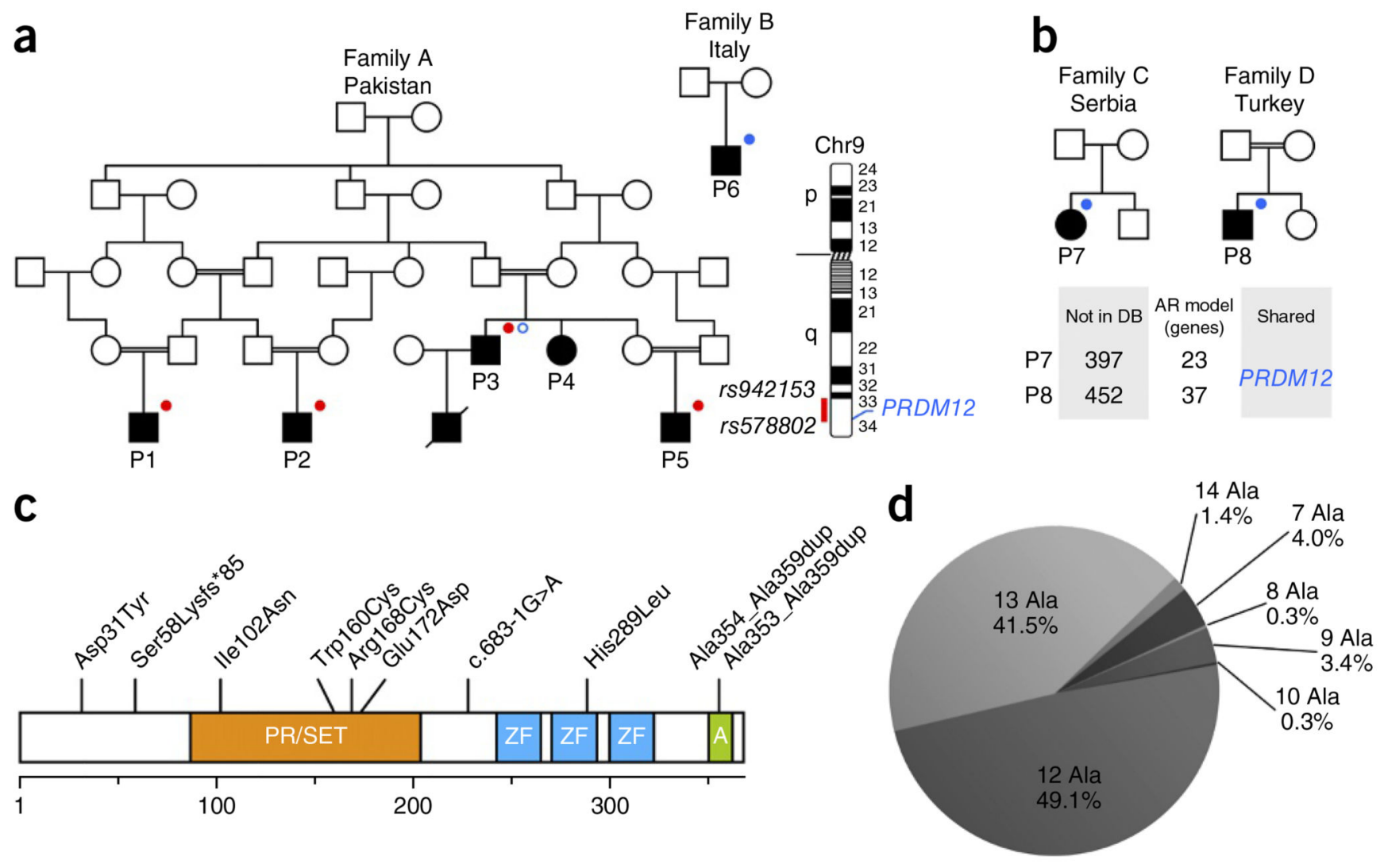

Figure 1. Identification of mutations in PRDM12.

(a) In Pakistani multiplex family A, SNP-based autozygosity mapping of four individuals (solid red circles) pinpointed a single candidate region on chromosome 9q33.2-34.13 (represented by reference SNP cluster (rs) numbers of flanking SNP markers and a red vertical bar next to the chromosome 9 ideogram). Although exome sequencing of the index patient from family A (open blue circle) yielded inconclusive results, one gene in the candidate region, PRDM12, harbored a candidate homozygous mutation in family B (solid blue circle). P1-P6, patients 1-6. (b) Exome sequencing of subjects from two families, family $\mathrm{C}$ and family $\mathrm{D}$ (solid blue circles). PRDM12 was the only gene containing potentially deleterious variants excluded from all databases ("Not in DB") on both alleles ("AR model") in both affected individuals ("Shared"). (c) Schematic representation of the PRDM12 protein and distribution of mutations. Amino acid numbering is shown along the bottom. PR/SET, PR domain; ZF, zinc finger motif; A, polyalanine tract. (d) Distribution of PRDM12 polyalanine tract lengths in the general population (176 individuals). 


\section{a}

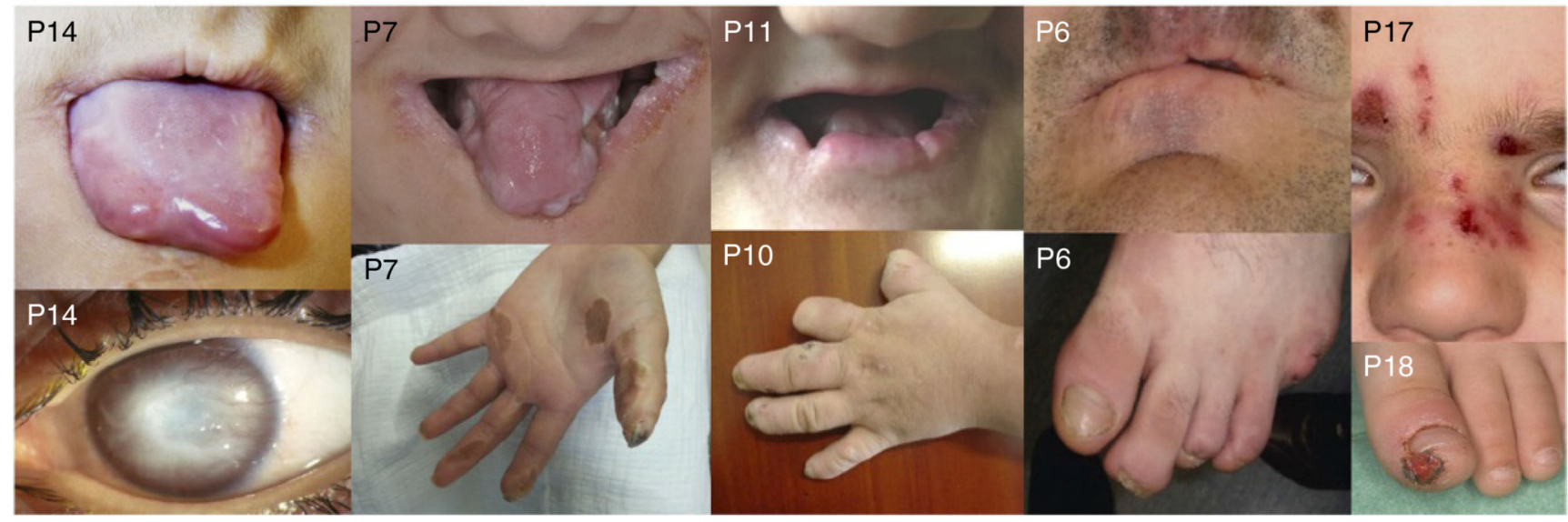

b
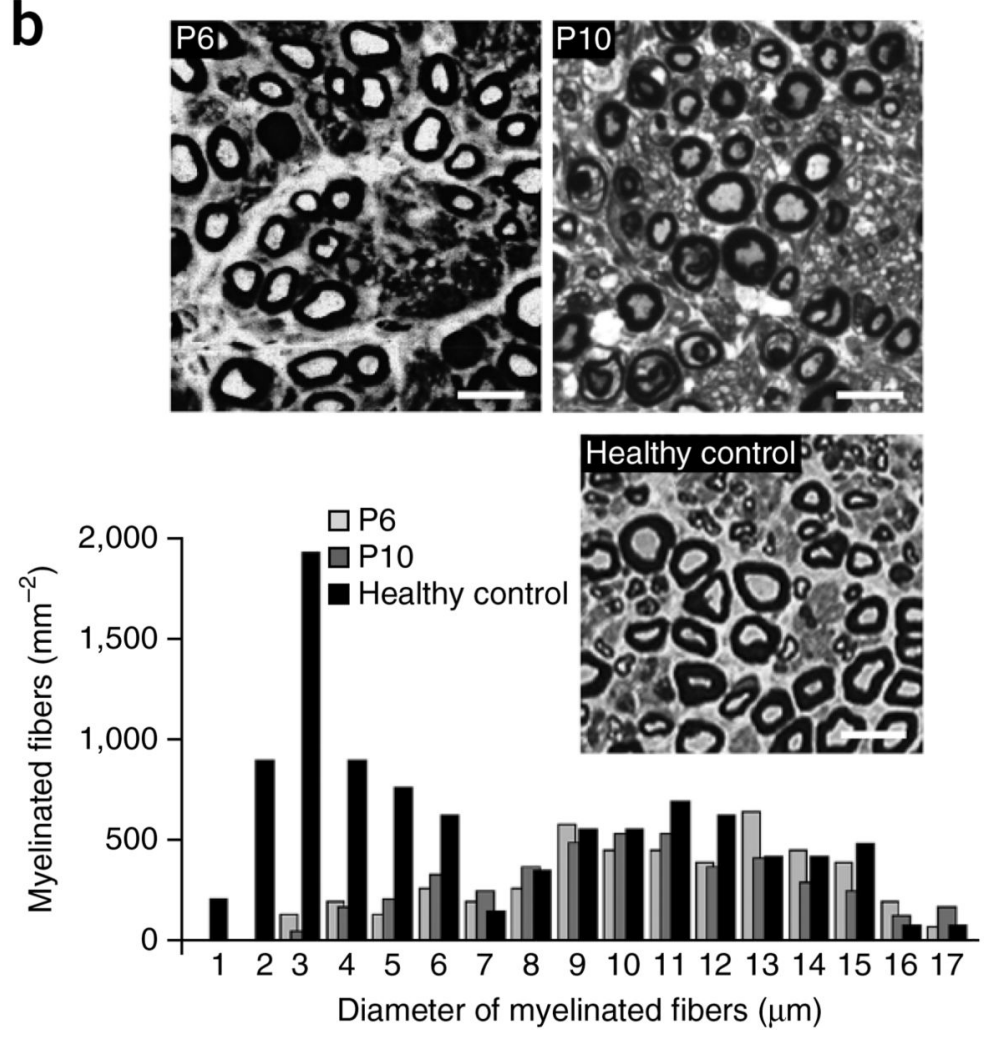

C Healthy control
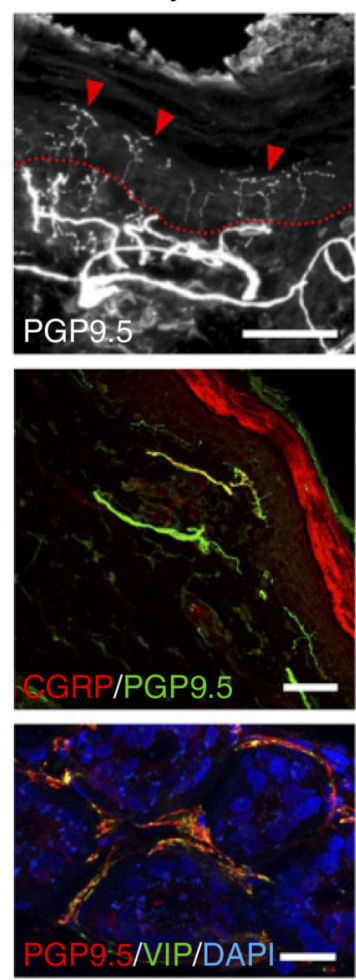

P11
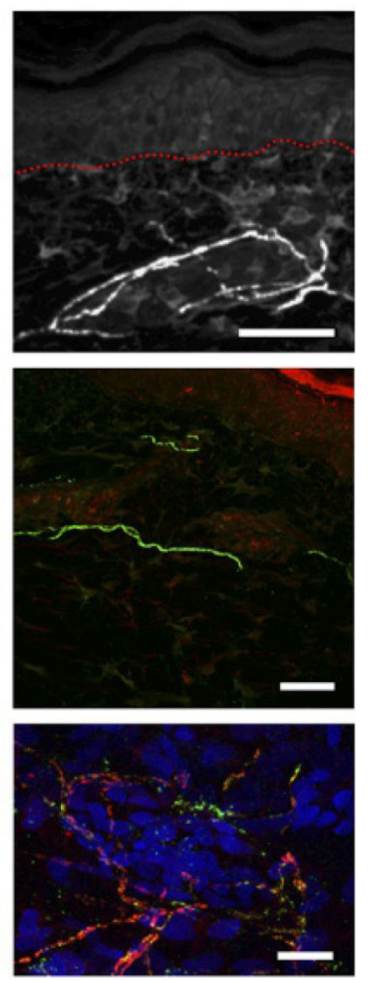

Figure 2. Phenotype of affected individuals with PRDM12 mutations.

(a) Mutilation of tongue and lips, corneal opacity, scarring and mutilation of distal phalanges. Patients P17 and P18 (family J) represented a milder phenotype with sequelae such as facial scratching and diabetes-like foot ulcers. Consent to publish images of the individuals was obtained. (b) Sural nerve biopsy specimens showing selective loss of smallcaliber myelinated axons. The total numbers of myelinated fibers per square millimeter were 4,692 (P6), 4,438 (P10) and 9,609 (healthy control). Semithin sections were stained with toluidine blue; scale bars, $20 \mu \mathrm{m}$. (c) Skin biopsies labeled with PGP9.5 (pan-neuronal marker), calcitonin gene-related peptide (CGRP, labeling a subpopulation of nociceptive 
primary afferents) and vasoactive intestinal peptide (VIP, a marker for autonomic nerve fibers). Although ample intraepidermal nerve endings (red arrowheads) were observed in the biopsy from a healthy donor, nerve fibers did not cross the dermal-epidermal border (red dashed line) in the affected subject's biopsy. In the biopsy from P11, dermal CGRPimmunoreactive nerve fibers were almost absent, and sweat glands were innervated by VIPimmunoreactive fibers, but at a reduced density. Scale bars, $50 \mu \mathrm{m}$ (top two rows) or $20 \mu \mathrm{m}$ (bottom row). 
a

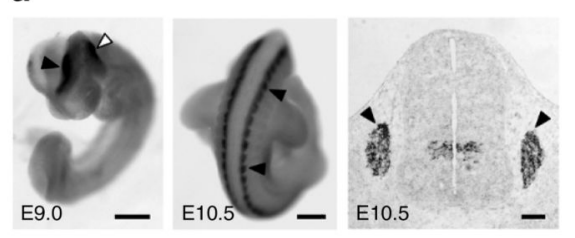

b

(bp)

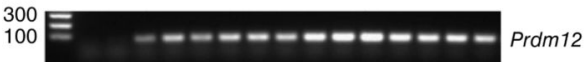

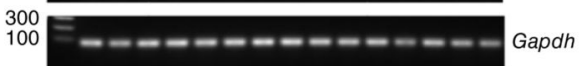

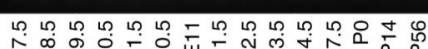

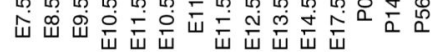

Embryo $\overline{\text { Neural }}$ DRG

C

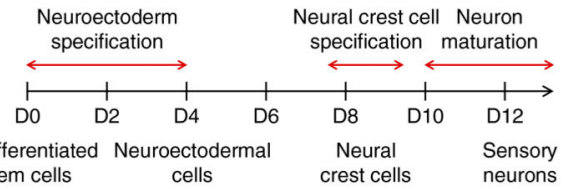

stem cells

cells

crest cells

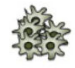

D0 D3 D5 D7 D9 D11 D13

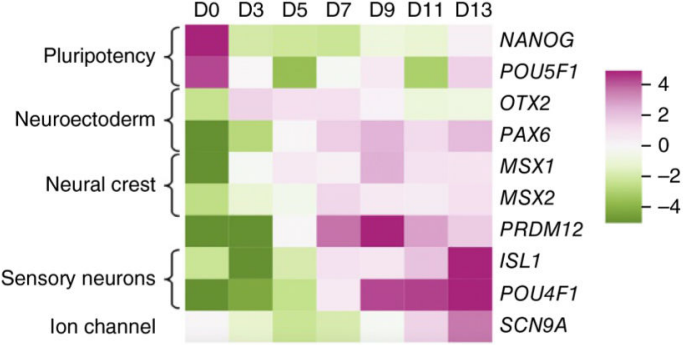

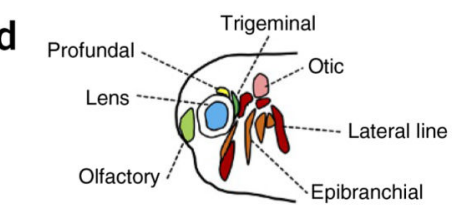
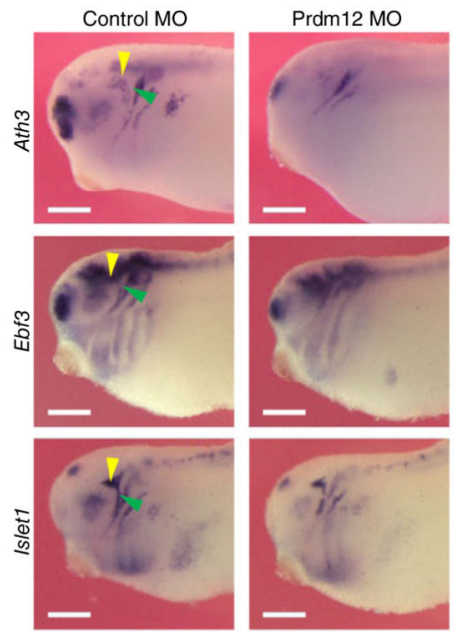

$\square$ Normal $\square$ Mildly abnormal $\square$ Severe defects

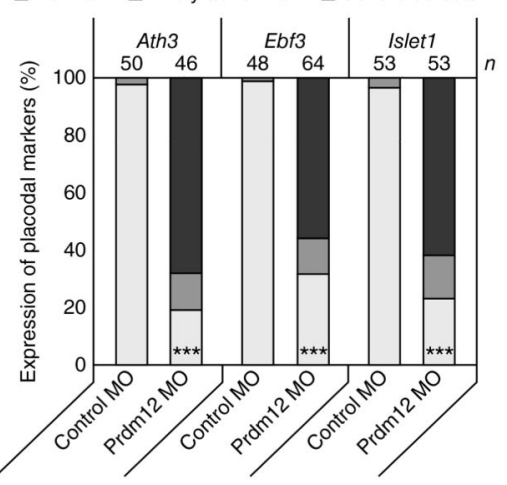

Figure 3. A role for Prdm12 in sensory neuron development.

(a) Whole-mount in situ hybridization of mouse embryos at E9.0 (left) identified expression of Prdm12 in neural folds (black arrowhead), which coincided with the earliest stage of neural crest cell delamination and migration (white arrowhead). In situ hybridization of whole embryos (middle) and transverse sections of cervical spinal cord (right) at E10.5 showed strong Prdm 12 expression in DRG (black arrowheads). Scale bars: left, $250 \mu \mathrm{m}$; middle, $500 \mu \mathrm{m}$; right, $100 \mu \mathrm{m}$. (b) RT-PCR analysis confirmed Prdm12 expression throughout the whole period of DRG development and sensory neuron differentiation (E9.5P14) and in mature DRG (P56). (c) Quantitative RT-PCR of human iPSC-derived sensory neurons showed that PRDM12 expression peaked during neural crest specification. Changes in the expression of pluripotency markers and canonical sensory neuron markers confirmed successful differentiation. The schematic drawing above the heat map illustrates the stages of development during the differentiation of sensory neurons. D, day of differentiation process. (d) Knockdown of Prdm12 by a specific morpholino (MO) in Xenopus embryos caused irregular staining for markers of cranial sensory placode development (Ath3, Ebf3 
and Islet1). Embryos injected with control MO or Prdm12 MO were analyzed at the late tailbud stage (stage 28) by whole-mount in situ hybridization; yellow arrowheads, profundal placode; green arrowheads, trigeminal placode. Scale bars, $200 \mu \mathrm{m}$. Normal gene expression domains of cranial placodes in Xenopus laevis are shown in the schematic drawing at the top of the panel (lateral view, late tailbud stage; modified from ref. 25). The results were categorized and quantified ( $n \geq 46$ live embryos per condition). Statistical differences between expression in control MO-treated and Prdm12 MO-treated embryos are indicated. *** $P<0.001$ (two-sided Mann-Whitney $U$-test). 
a
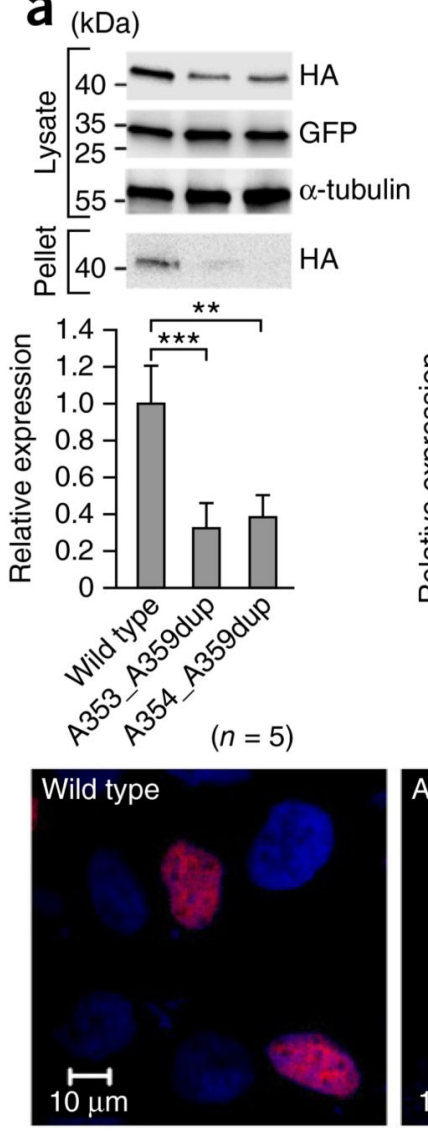

d

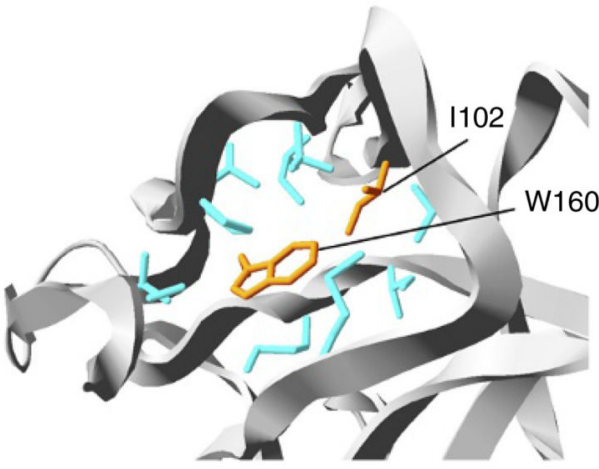

\section{A353_A359dup}
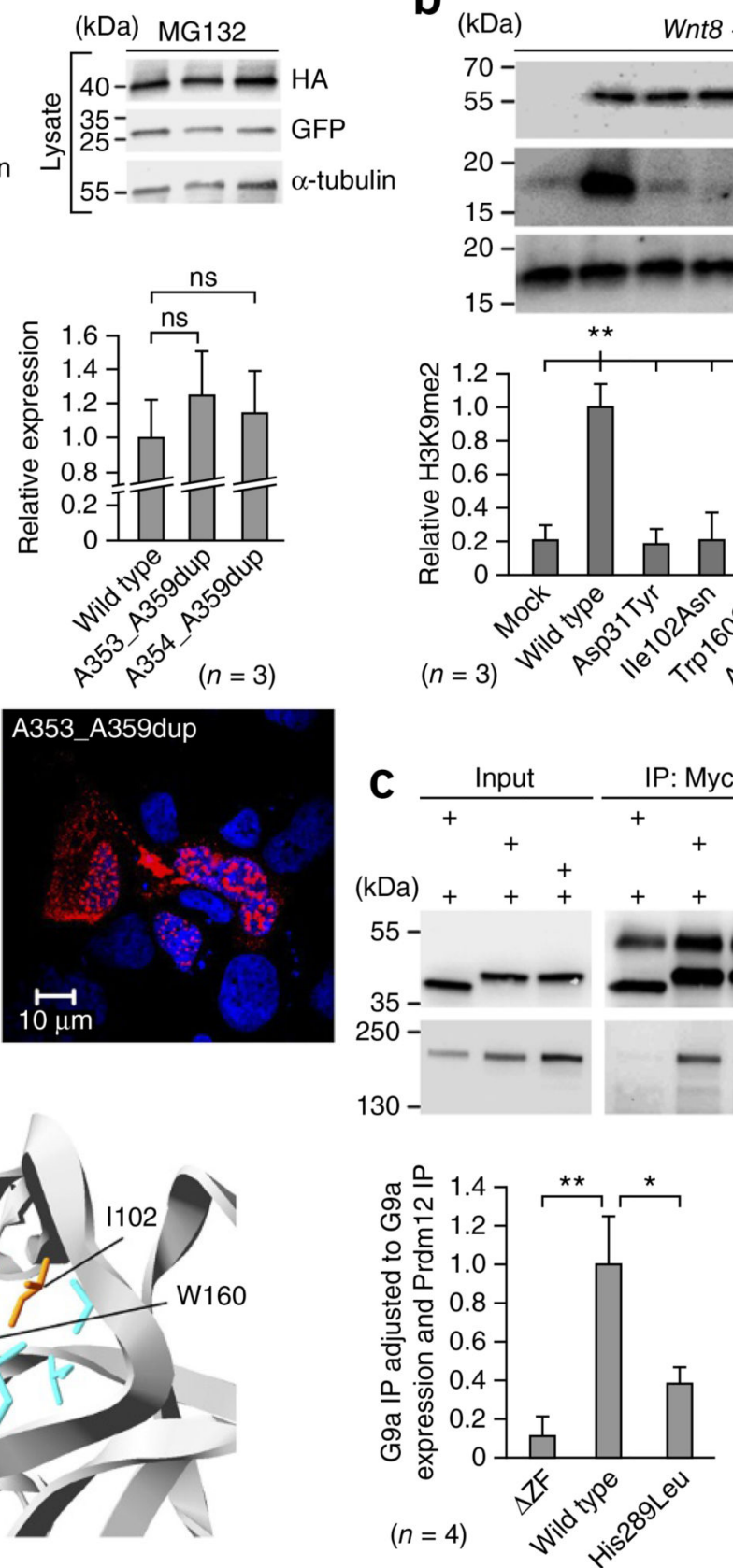

b

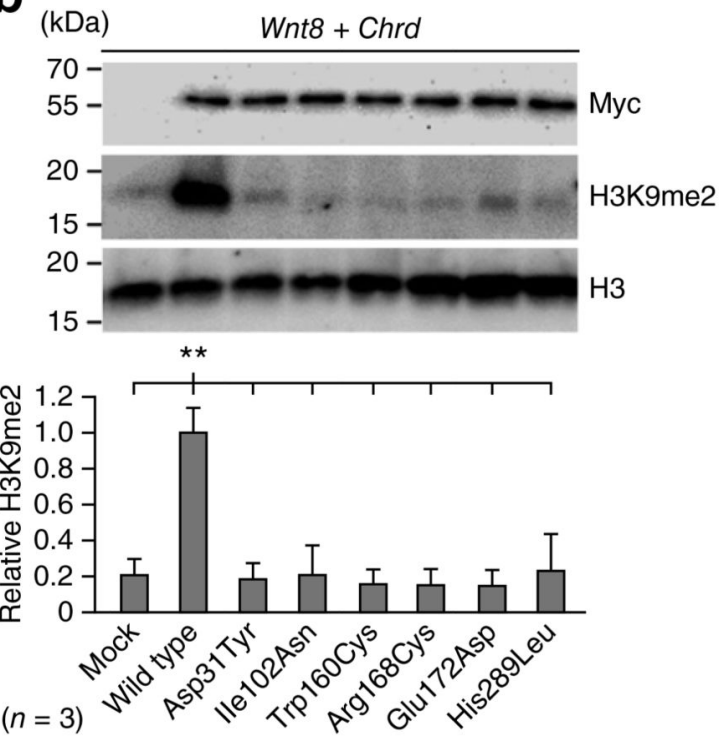

$(n=3)$

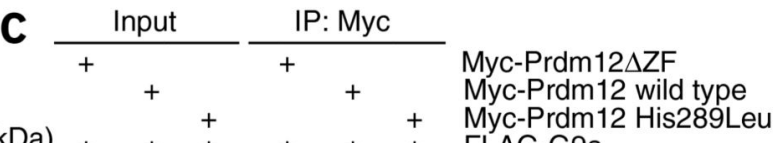
Myc-Prdm12 wild type FLAG-G9a IgG heavy chain Myc

Figure 4. Consequences of PRDM12 mutations.

(a) The hemagglutinin (HA)-tagged PRDM12 polyalanine expansion mutant showed lower expression levels in COS-7 cells than did wild-type PRDM12; expression was recovered by MG132. HA-PRDM12 signals were normalized to those of a-tubulin and GFP (transfectionefficiency control). The transfected mutant formed aggregates in the nucleus and cytoplasm in HEK-293T cells (bottom). Red, PRDM12 (fluorescent detection of the anti-HA tag); blue, nuclei (DAPI staining). (b) Wild-type Prdm12 induced robust dimethylation on H3K9 in Xenopus neurula, but CIP-associated missense mutants were functionless. Xenopus animal 
cap cells were microinjected with Myc-Prdm12 (wild type and mutant), Wnt8 and Chrd mRNA and cultured until mid-neurula stage (stage 15). H3K9me2 signals were normalized to Prdm12 (Myc) and total H3. (c) The p.His289Leu alteration impairs Prdm12-G9a interaction. Myc-Prdm12 and FLAG-G9a were expressed in COS-7 cells (Input) and immunoprecipitated using anti-Myc (IP: Myc). Bound G9a was normalized to amounts of Prdm12 in the immunoprecipitation (IP) fraction and G9a protein in the lysate. According to the structural model for the PRDM12 zinc finger domains, His289 (orange) is one of the residues (cyan) that coordinate the zinc ion. Prdm $12 \Delta \mathrm{ZF}$ is an artificial mutant lacking zinc fingers. IgG, immunoglobulin G. (d) Mutation-altered residues Ile102 and Trp160 (orange) have hydrophobic interactions with other residues (cyan) in the core of the PRDM12-PR domain. Introduction of a polar side chain (p.Ile102Asn) or a disulfide-bond partner (p.Trp160Cys) into the hydrophobic core may affect the structure of the PR domain. The bar graphs in a-c represent mean values of $n$ biological replicates, and error bars represent s.d. Statistical differences between control (wild type) and Prdm12 mutants are indicated. ns, not significant. $* P<0.05, * * P<0.01, * * * P<0.001$ (Welch's $t$-test). 